\title{
Des mutants virulents et hypervirulents de virus de I'immunodéficience simienne (SIV)
}

Il est bien établi que les rétrovirus en général, ceux de l'immunodéficience en particulier, ont un génome " instable ", subissant des mutations à un rythme accéléré. Ces mutations, qui posent problème pour le développement d'une vaccination efficace du fait des variations antigéniques qu'elles provoquent, sont également susceptibles de modifier la virulence et la pathogénicité des mutants. Cela vient d'être illustré de façon tout à fait remarquable par deux articles montrant que des virus de l'immunodéficience simienne (SIV) avaient acquis une pathogénécité dont ils étaient initialement dépourvus. L'équipe de R. Desrosiers (Harvard Medical School, MA, USA), en association avec des chercheurs californiens, a étudié un variant du virus SIV $_{\text {MAC }}$, infectant normalement les macaques et probablement dérivé de SIV $_{\text {SmM }}$ qui est le virus des cercocébes (ou mangabey couleur de suies) $\left(\mathrm{m} / \mathrm{s}, n^{\circ} 7\right.$, vol. 6, p. 696). L'ADN cloné d'un isolat particulier a été transféré dans des cellules de macaque en culture et des singes Rhesus ont été inoculés avec les virus produits ex vivo. Cinquante pour cent des animaux ainsi inoculés développèrent un syndrome d'immunodéficience très proche du SIDA, mortel en un an. La comparaison des séquences nucléotidiques de génomes infectieux et non infectieux montre un petit nombre de différences sans qu'il soit possible pour l'instant d'attribuer avec certitude à l'une d'entre elles un rôle prépondérant dans l'acquisition $\mathrm{du}$ caractère pathogène. Une telle étude corrélant la pathoginicité à la séquence du génome viral, par comparaison entre différents isolats et par mutagenèse in vitro, devrait néanmoins permettre d'identifier, à terme, les déterminants de la pathogénécité. Dans le cas du génome de l'isolat virulent de SIV $_{\text {MAC }}$, l'attention peut être attirée par une mutation non-sens (un codon stop en position 93) dans le gène nef, car celui-ci joue normalement un rôle inhibiteur sur l'expression du génome viral.

D'autres équipes américaines associées - de l'université Harvard (Boston, MA), d'Atlanta (GE) et de Stanford (CA) - ont rapporté un résultat encore beaucoup plus étonnant: un isolat de SIV $_{\text {SMM }}$, dénommé par les auteurs SIV $_{\text {SMM }}$. ${ }_{\mathrm{PB} j 14}$, provoque chez des macaques à queue de cochon une maladie aiguë ressemblant à une entéropathie fulminante, mortelle en une semaine dans un tableau de diarrhées profuses. Le mécanisme de cette affection semble être une infiltration massive de l'intestin par des lymphocytes dans lesquels le virus se développe très activement, provoquant probablement, par le jeu des cytokines libérées, une activation d'autres cellules, notamment de macrophages, et la production de TNF (tumor necrosis factor). Le TNF est également impliqué dans la pathogénie du choc septique endotoxinique. Au point de vue moléculaire, une différence d'importance potentielle entre le génome du variant hypervirulent et ceux de SIV $_{\text {SMM }}$ avirulents est une duplica- tion dans le LTR du site de fixation pour la protéine activatrice de la transcription $\mathrm{NF}-\kappa \mathrm{B}$.

Ces résultats peuvent laisser espérer que les mécanismes de la pathogénicité des virus de l'immunodéficience seront bientôt élucidés. Ils sont également générateurs d'espoir, car les singes infectés par des isolats avirulents de SIV $_{\text {SMM }}$ sont immunisés contre SIV $_{\mathrm{SMM}-\mathrm{PBj}_{14} \text {, ce }}$ qui montre, malgré tout, qu'une immunisation protectrice est possible. Il y a aussi, malheureusement, certains aspects de ces informations qui sont fort inquiétants : des mutations d'un lentivirus de type HIV, provoquant normalement une affection d'évolution lente, peuvent aboutir à un agent hypervirulent ne méritant plus du tout le qualificatif de "lenti". Enfin, mais cette précision est à peine utile, le déclenchement d'un syndrome infectieux, mimant le SIDA dans l'observation de l'isolat virulent de $\mathrm{SIV}_{\mathrm{MAC}}$, par un virus régénéré à partir de son génome cloné, prouve bien que ce virus est le responsable de l'affection, n'en déplaise à P.H. Duesberg $\left(\mathrm{m} / \mathrm{s}, \mathrm{n}^{\circ} 2\right.$, vol. 5, p. 117).

A. $\mathbf{K}$.

1. Kestler $\mathrm{H}$, Kodamat $\mathrm{T}$, Ringler $\mathrm{D}$, et al. Induction of AIDS in Rhesus monkeys by molecularly cloned simian immunodeficiency virus. Science $1990 ; 248: 1109-12$ 2. Dewhurst S, Embretson JE, Anderson DC, Mullins JI, Fultz PN. Sequence analysis and acute pathogenicity of molecularly clones SIV $_{\text {SMM-PBi14. Nature } 1990 ; 345}$ 635-40. 